\title{
Performance Evaluations of lon Exchanged Zeolite Membranes on Alumina Supports
}

\section{Nuclear Technology}

Research and Development

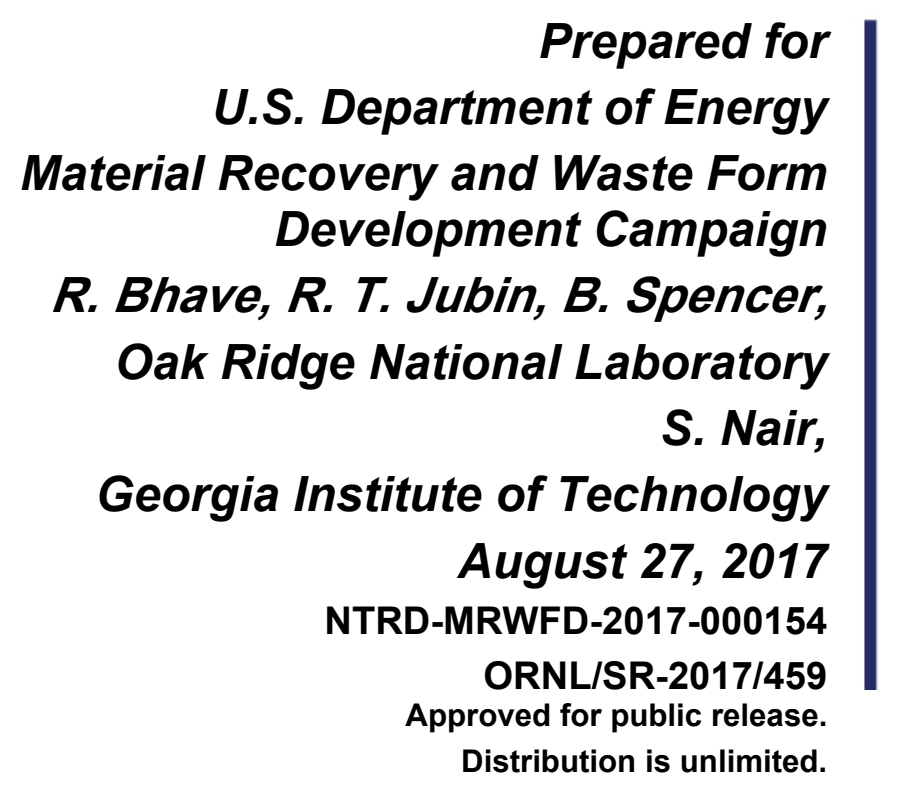





\section{DISCLAIMER}

This information was prepared as an account of work sponsored by an agency of the U.S. Government. Neither the U.S. Government nor any agency thereof, nor any of their employees, makes any warranty, expressed or implied, or assumes any legal liability or responsibility for the accuracy, completeness, or usefulness, of any information, apparatus, product, or process disclosed, or represents that its use would not infringe privately owned rights. References herein to any specific commercial product, process, or service by trade name, trade mark, manufacturer, or otherwise, does not necessarily constitute or imply its endorsement, recommendation, or favoring by the U.S. Government or any agency thereof. The views and opinions of authors expressed herein do not necessarily state or reflect those of the U.S. Government or any agency thereof. 



\section{SUMMARY}

This report describes the synthesis and evaluation of molecular sieve zeolite membranes to separate and concentrate tritiated water (HTO) from dilute HTO-bearing aqueous streams. In the first phase of this effort, several monovalent and divalent cation-exchanged silico alumino phosphate (SAPO-34) molecular sieve zeolite membranes were synthesized on disk supports and characterized with gas and vapor permeation measurements. In the second phase, Linde Type A (LTA) zeolite membranes were synthesized in disk and tubular supports. The pervaporation process performance was evaluated for the separation and concentration of tritiated water.

Experiments were performed using tritiated water feed solution containing tritium at the high end of the range $(1 \mathrm{mCi} / \mathrm{mL})$ anticipated in a nuclear fuel processing system that includes both acid and water streams recycling. The tritium concentration was about $0.1 \mathrm{ppm}$. The permeate was recovered under vacuum. For the ion exchanged SAPO-34 zeolite membranes the $\mathrm{HTO} / \mathrm{H}_{2} \mathrm{O}$ selectivity and separation factor calculated from the measured tritium concentrations ranged from 0.99 to 1.23 , and $0.83-0.98$, respectively. Ion exchanged K-LTA membranes performed better with a separation factor ranging from 1.3 to 2.79. Due to the high water permeance, HTO is retained and concentrated on the feed side compared to SAPO membranes where HTO was slightly more concentrated in the permeate.

This report discusses several encouraging observations including molecular sieving and high vapor permeance suggesting a path forward to further improve both permeance and separation factor. New approaches are proposed to tune the sorption and diffusion properties offered by small pore LTA zeolite materials, including variation of aluminosilicate composition to enhance separation factor and chemical stability. It is hypothesized that substantially improved preferential transport of $\mathrm{H}_{2} \mathrm{O}$ over $\mathrm{HTO}$ will result in a more concentrated retentate in a staged cascade system. 


\section{CONTENTS}

SUMMARY

Acronyms

1. INTRODUCTION

2. MATERIALS AND METHODS

2.1 SAPO-34 and ion exchanged SAPO-34 membrane synthesis ..............................................2

2.2 Synthesis of $\mathrm{NaA}$ and KA zeolite membranes ..................................................................2

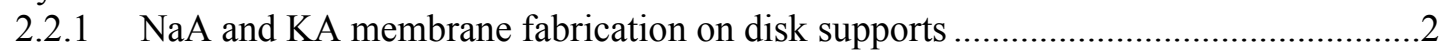

2.2.2 NaA and KA membrane fabrication on tubular supports ..........................................

2.3 Characterization of SAPO-34 and ion-exchanged SAPO membranes ...................................

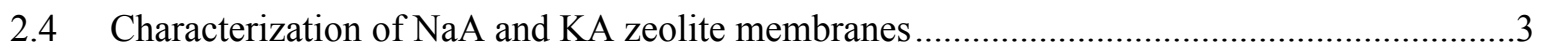

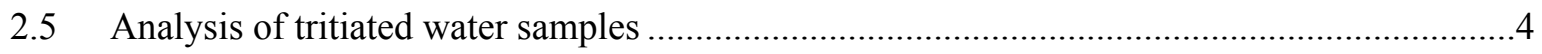

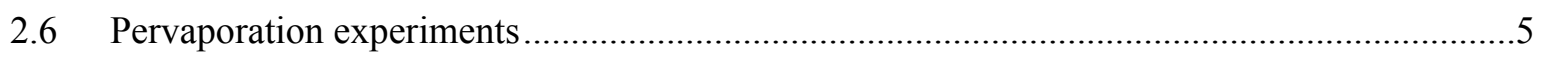

3. RESULTS AND DISCUSSION

4. FUTURE STUDIES

5. REFERENCES

\section{FIGURES}

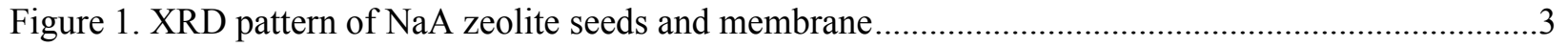

Figure 2. Surface and cross-sectional SEM images of KA zeolite membrane ..........................................

Figure 3. Schematic of the pervaporation system for the separation of tritiated water ...............................5

TABLES

Table 1. Vapor permeation characteristics of SAPO-34 and cation exchanged SAPO-34

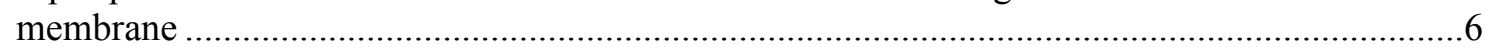

Table 2. Separation of HTO with Na- and K-LTA zeolite membranes on disk supports...........................7

Table 3. Separation of HTO with K-LTA zeolite membranes on tubular supports.....................................

Table 4. Material balance for HTO separation with K-LTA zeolite membranes on tubular supports 


\section{ACRONYMS}

$\begin{array}{ll}\mathrm{Bq} & \text { Becquerel } \\ \text { CECE } & \text { combined electrolysis and catalyst exchange } \\ \mathrm{D}_{2} \mathrm{O} & \text { deuterium oxide } \\ \text { DPA } & \text { di- } n \text {-propylamine } \\ \text { FTIR } & \text { Fourier Transform Infrared Spectroscopy } \\ \text { GPU } & \text { gas permeation unit }\left(\mathrm{cm}^{3} / \mathrm{cm}^{2}-\mathrm{sec}-\mathrm{cm} \mathrm{Hg}\right) \\ \mathrm{HDO} & \text { heavy (or deuterated) water } \\ \mathrm{H}_{2} \mathrm{O} & \text { water containing only hydrogen-1 } \\ \mathrm{HTO} & \text { tritiated water } \\ \text { ISS } & \text { isotope separation system } \\ \text { ITER } & \text { international thermonuclear experimental reactor } \\ \text { LSA } & \text { liquid scintillation analyzer } \\ \text { LTA } & \text { Linde type A zeolite } \\ \text { LUDOX } & \text { colloidal silica } \\ \text { mCi } & \text { milli Curie }\left(3.7 \times 10^{7} \text { Bq) }\right. \\ \text { PMR } & \text { palladium membrane reactor } \\ \text { SAPO-34 } & \text { silico alumino phosphate zeolite } \\ \text { XRD } & \text { X-ray diffraction }\end{array}$





\section{TRITIUM SEPARATION FROM HIGH VOLUME DILUTE AQUEOUS STREAMS}

\section{INTRODUCTION}

The release of tritium [usually as tritiated water (HTO)] from nuclear facilities poses a serious hazard to the environment necessitating tritium abatement on aqueous streams generated from various nuclear operations. There are several sources of tritium in nuclear enterprises such as light and heavy waterpower reactors, nuclear fuel cycle, and the International Thermonuclear Experimental Reactor (ITER). In nuclear fuel reprocessing, process water and acid water streams are recycled and are contaminated with tritiated water.

A novel separation process that utilizes molecular sieve membranes capable of preferentially separating tritium from dilute HTO-bearing aqueous streams is under investigation. The use of membranes for radioactive decontamination and tritium separation is detailed in the literature, ${ }^{1-3}$ but the proposed approach of utilizing molecular sieve membranes on robust high-surface area supports has not been reported. Traditional tritium separation technologies include combined electrolysis and catalytic exchange (CECE), palladium membrane reactor (PMR), and the highly energy intensive cryogenic distillation. ${ }^{4-11}$ CECE is generally recognized as the current state of the art for decontamination of tritium in light water and heavy water (HDO) nuclear power reactors where HDO is used both as a reactor moderator and coolant.

An alternative technology utilizing zeolite molecular sieve membranes was evaluated, which may demonstrate significantly lowered energy requirement over the available technologies for tritium separation. Membrane-based tritium concentration, the subject of this effort, may offer several advantages over the current state of the art. The membrane system is relatively easy to fabricate and directly scalable to handle large volume dilute streams with low operating cost. The low-cost operating features include separation and concentration at ambient temperature and low pressure compared to CECE, cryogenic distillation or PMR systems. Tritium removal from light and heavy water reactors is described with the application of combined electrolysis and catalyst exchange in U.S. and Canadian patent applications. ${ }^{5,6}$ However, the process has several limitations including low separation factor, high energy requirements, and may not be well-suited to treat large volume dilute solutions since the treatment cost is directly dependent on processing volume. The process also requires careful balance of concentration profiles in the column which is packed with a hydrophobic catalyst and inert packing material to promote isotopic exchange between the aqueous solution and gaseous hydrogen.

SAPO-34 is a neutral uncharged zeolite material. ${ }^{10}$ It has been reported that the self-diffusion of several isotopic species of water such as $\mathrm{H}_{2} \mathrm{O}, \mathrm{HDO} / \mathrm{D}_{2} \mathrm{O}$ (heavy water) and $\mathrm{HTO} / \mathrm{T}_{2} \mathrm{O}$ (tritiated water) can be significantly modified in cation exchanged zeolite or molecular sieve sorbents. ${ }^{9}$ A previous report evaluated the feasibility of separating tritium by taking advantage of the differences in adsorption and diffusion rates using cation exchanged zeolite molecular sieve membranes. This research report extends this evaluation to the use of ion-exchanged Linde Type A zeolite (LTA) membranes as an alternative to SAPO-34 zeolite membranes. It describes the tritiated water (HTO) separation and $\mathrm{HTO} / \mathrm{H}_{2} \mathrm{O}$ separation factor using ion exchanged LTA membranes prepared on alumina disk and tubular supports to assess their feasibility for the concentration of tritiated water.

The HTO concentration in tritiated water can be in the range of 200 to $1,000 \mathrm{Ci} / \mathrm{m}^{3}$ or $0.2-1 \mathrm{mCi} / \mathrm{mL}$. The HTO concentration of approximately $1 \mathrm{mCi} / \mathrm{mL}$, which is at the upper end of the range, was used in this study. It should be noted that these concentrations are at least three orders of magnitude lower than HDO concentration in water recycle streams in heavy water nuclear power reactors. 


\section{MATERIALS AND METHODS}

\subsection{SAPO-34 and ion exchanged SAPO-34 membrane synthesis}

SAPO-34 crystals were first synthesized prior to the preparation of SAPO-34 membranes. Aluminum isopropoxide, $\mathrm{LUDOX}^{\circledR}$ colloidal silica and $\mathrm{H}_{3} \mathrm{PO}_{4}$ were used as $\mathrm{Al}, \mathrm{Si}$ and $\mathrm{P}$ source, respectively. The crystals were synthesized at $210{ }^{\circ} \mathrm{C}$ for $24 \mathrm{~h}$ by the hydrothermal synthesis method. The molar composition of the SAPO-34 crystals synthesis solution was $1.0 \mathrm{Al}_{2} \mathrm{O}_{3}: 1.0 \mathrm{P}_{2} \mathrm{O}_{5}: 0.32 \mathrm{SiO}_{2}: 1.0$ TEAOH:0.8 DPA: $52 \mathrm{H}_{2} \mathrm{O}$. H-SAPO-34 membranes were prepared by secondary growth on disk-type $\alpha$ alumina supports $(25.4 \mathrm{~mm}$ diameter and $1 \mathrm{~mm}$ thickness, Coorstek). The substrates were seeded using the smaller-size SAPO-34 crystals via the steam-assisted conversion (SAC) method. The seed crystals were added to a synthesis mixture that had a molar composition of $1.0 \mathrm{Al}_{2} \mathrm{O}_{3}: 2.0 \mathrm{P}_{2} \mathrm{O}_{5}: 0.6 \mathrm{SiO}_{2}: 4.0$ TEAOH: $75 \mathrm{H}_{2} \mathrm{O}$. The seeds/synthesis mixture ratio was $15 \mathrm{mg} / \mathrm{g}$. After evaporating $90 \%$ water from the mixture at $353 \mathrm{~K}$ and converting the synthesis mixture into a gel-like paste, the disk support was handcoated with the paste containing the seeds. The substrates were then dried for $2 \mathrm{~h}$ at $323 \mathrm{~K}$ and subsequently placed in Parr autoclaves with $5 \mathrm{~mL}$ of DI water introduced at the bottom. The SAC process was then carried out at $473 \mathrm{~K}$ for $24 \mathrm{~h}$ in order to convert the paste coating into continuous seed layer. Well-intergrown SAPO-34 membranes were then prepared from the post-SAC substrates by contacting them with a synthesis mixture of molar composition $0.85 \mathrm{Al}_{2} \mathrm{O}_{3}: 1.0 \mathrm{P}_{2} \mathrm{O}_{5}: 0.6 \mathrm{SiO}_{2}: 1.75$ TEAOH:155 $\mathrm{H}_{2} \mathrm{O}$. The seeded substrate was placed vertically in a Parr autoclave and hydrothermal growth was carried out at $483 \mathrm{~K}$ for $6 \mathrm{~h}$. The membranes were calcined at $823 \mathrm{~K}$ for $6 \mathrm{~h}$ in stagnant air using a slow $0.5 \mathrm{~K} / \mathrm{min}$ heating and cooling rate to avoid potential cracks caused by rapid temperature changes. The acetate salts of various ions $\left(\mathrm{Li}^{+}, \mathrm{Na}^{+}, \mathrm{K}^{+}\right.$, and $\left.\mathrm{Co}^{2+}\right)$ dissolved in ethanol and chloride salts of divalent cations $\left(\mathrm{Mg}^{2+}\right.$ and $\mathrm{Sr}^{2+}$ ) were used to introduce cations in $\mathrm{H}$-SAPO-34. For barium cation exchange, barium chloride dissolved in methanol was prepared. ${ }^{12}$

\subsection{Synthesis of $\mathrm{NaA}$ and KA zeolite membranes}

\subsubsection{NaA and KA membrane fabrication on disk supports}

Aluminosilicate zeolites such as Na-LTA (Linde Type A zeolite) were synthesized and characterized for their permeance and ion exchange properties. LTA zeolites were evaluated as they provide superior cation exchange capacity ( 1 cation per aluminum atom) which is anticipated to increase HTO permeance and selectivity. Na-LTA crystals were hydrothermally synthesized and the synthesis solution was sealed in a Teflon liner at $100{ }^{\circ} \mathrm{C}$ for 12 hours. This was followed by calcination at $500{ }^{\circ} \mathrm{C}$ for 6 hours to remove the templates. The disk type $\alpha$-alumina supports were seeded using the hot dip coating method. The seeded supports were placed vertically in a Teflon liner and membrane synthesis was carried at $80{ }^{\circ} \mathrm{C}$ for 5 hours. The seed zeolite crystals and the Na-LTA membranes were characterized by X-ray diffraction (XRD). The surface and cross-section morphologies of crystals and membranes were observed by scanning electron microscopy (SEM). The quality and integrity of the synthesized membrane was good, showing no defects and a dense uniform smooth surface. Na-LTA zeolite membranes were first synthesized followed by ion exchange with $1 \mathrm{M}$ potassium chloride $(\mathrm{KCl})$ at $40{ }^{\circ} \mathrm{C}$ to form the K-LTA zeolite membrane on porous alumina support.

\subsubsection{NaA and KA membrane fabrication on tubular supports}

$\mathrm{NaA}$ membranes were prepared by secondary growth on tubular-type $\alpha$-alumina supports (10 mm O.D, 7 $\mathrm{mm}$ I.D. and $1.5 \mathrm{~mm}$ thickness, Inopor $\mathrm{GmbH}$ ). The substrates were seeded using the NaA crystals via dip coating method. The seed crystals were synthesized with a synthesis mixture which had a molar composition of $1.0 \mathrm{Al}_{2} \mathrm{O}_{3}: 2.0 \mathrm{SiO}_{2}: 5.0 \mathrm{Na}_{2} \mathrm{O}: 200 \mathrm{H}_{2} \mathrm{O}$. Al source was alumina isopropoxide, Na source was sodium hydroxide, and LUDOX-AS40 was used as Si source. The synthesis solution was mixed at $323 \mathrm{~K}$ for 24 hours. Seed crystals were washed until $\mathrm{pH}$ became neutral and dispersed in DI water to a concentration of $1 \mathrm{wt} . \%$. The tubular substrate was dip-coated for $30 \mathrm{sec}$, followed by drying at $333 \mathrm{~K}$ for 
24 hours to obtain the seed coated tubular alumina support. The seed-coated tubular alumina support was placed in a Teflon vessel containing $\mathrm{NaA}$ zeolite solution prepared using the $1.0 \mathrm{Al}_{2} \mathrm{O}_{3}: 2.0 \mathrm{SiO}_{2}: 3.4$ $\mathrm{Na}_{2} \mathrm{O}: 155 \mathrm{H}_{2} \mathrm{O}$ molar composition before placing the vessel in the autoclave apparatus and the hydrothermal growth was carried out at $373 \mathrm{~K}$ for 3 hours. To improve the formation of tubular NaA zeolite membrane on the alumina support, each membrane was synthesized twice (double-stage synthesis). The composition of second stage synthesis solution was $1.0 \mathrm{Al}_{2} \mathrm{O}_{3}: 5.0 \mathrm{SiO}_{2}: 50 \mathrm{Na}_{2} \mathrm{O}: 1000$ $\mathrm{H}_{2} \mathrm{O}$ and was heated to $343 \mathrm{~K}$ for 11 hours. Synthesized membranes were washed thoroughly with DI water for 12 hours. The synthesized $\mathrm{NaA}$ zeolite membranes were ion-exchanged with $1 \mathrm{M}$ aqueous solution of potassium chloride for 1 hours and the ion-exchange procedure was repeated three times.

\subsection{Characterization of SAPO-34 and ion-exchanged SAPO membranes}

The SAPO-34 seed crystals and membrane were characterized by X-ray diffraction (XRD), and the synthesized membranes were tested for single-gas permeation in which the driving force is a pressure gradient. The XRD patterns were analyzed solely to confirm the previously known and established phase identification of the synthesized seed crystals. The XRD analysis and permeation measurement results showed that high quality membranes were synthesized which are well suited to evaluate the vapor sorption and diffusion through the zeolite pores on tritiated water feed. ${ }^{12}$

\subsection{Characterization of $\mathrm{NaA}$ and KA zeolite membranes}

XRD patterns of as-synthesized NaA seeds and membrane are shown in Figure 1. The characteristic peaks associated with LTA structure are detected in XRD pattern and it is confirmed that no other competing phases are formed during synthesis.

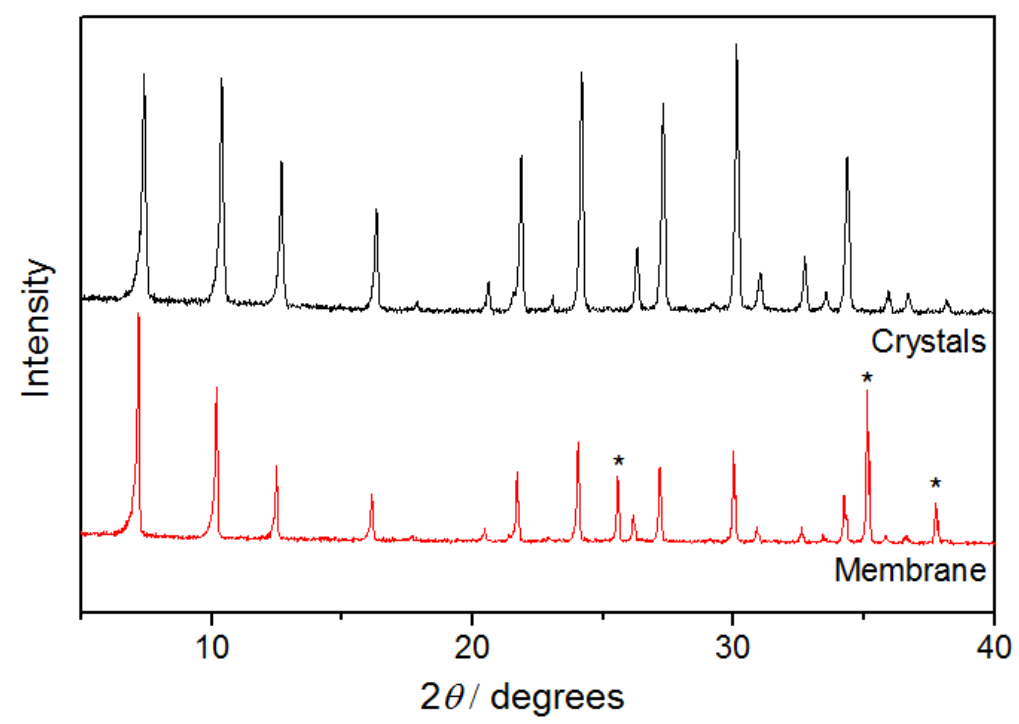

Figure 1. XRD pattern of NaA zeolite seeds and membrane

The bulk compositions of the as-synthesized $\mathrm{NaA}$ and cation-exchanged KA membranes were determined using EDX analysis of the Na, K, Si and Al content. The composition (expressed on a unit-cell basis) of $\mathrm{NaA}$ membrane was estimated as $\mathrm{Na}_{10.5} \mathrm{Si}_{12.4} \mathrm{Al}_{11.6} \mathrm{O}_{48}$. After three times of repeated ion exchange $(1 \mathrm{~h}$ for each exchange), almost $95 \%$ of sodium ions were exchanged to potassium ions with the composition of $\mathrm{K}_{10.2} \mathrm{Na}_{0.5} \mathrm{Si}_{12.2} \mathrm{Al}_{11.8} \mathrm{O}_{48}$. 
SEM images of ion-exchanged LTA membrane (KA) are shown in Figure 2. A dense and integrated zeolite layer can be seen on the surface of the substrate. Different from the membrane synthesized on the macroporous disk support (CoorsTek), seed/gel penetration is not found inside the support material, which is due to the small pore size $(\sim 100 \mathrm{~nm})$ of top layer of the tubular substrate. The thickness of the membrane was estimated to be $\sim 2.5 \mu \mathrm{m}$.
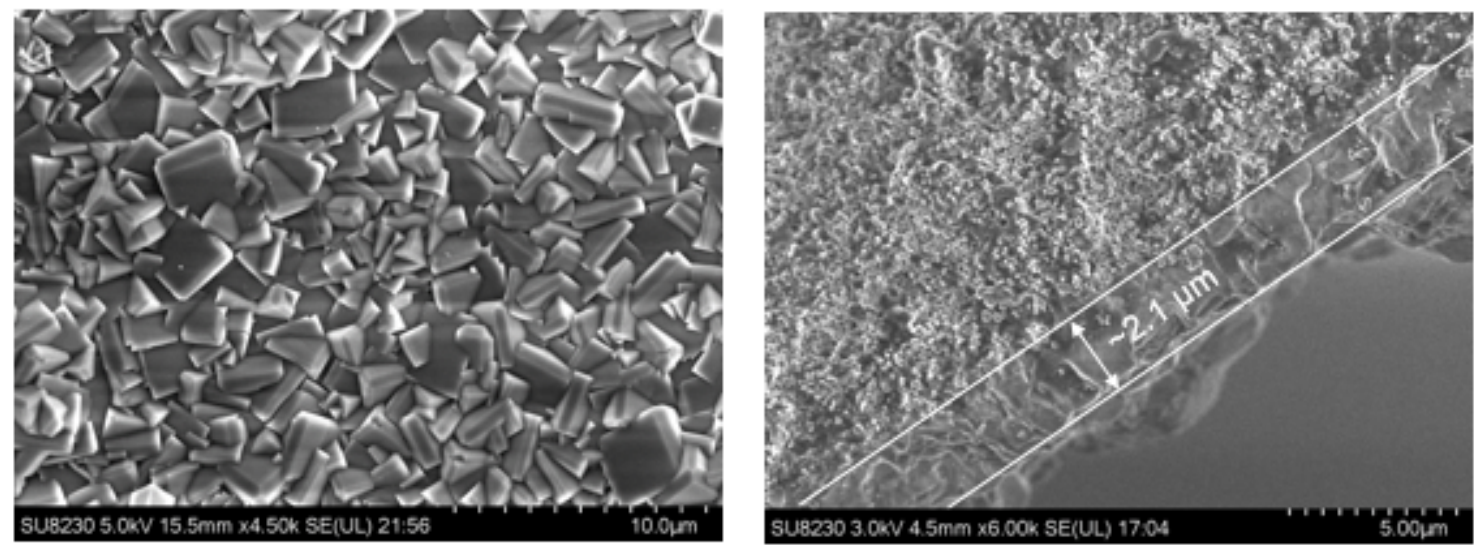

Figure 2. Surface and cross-sectional SEM images of KA zeolite membrane

\subsection{Analysis of tritiated water samples}

The analysis of HTO concentration in the feed and permeate from the pervaporation system was performed using a Liquid Scintillation Analyzer (LSA). The concentration (radioactivity) was measured in Becquerel $/ \mathrm{mL}(\mathrm{Bq} / \mathrm{mL})$. The error in the measurement of HTO concentration is estimated to be $1-2 \%$, and the error in the calculated HTO permeance is $<5 \%$.

The separation factor of $\mathrm{HTO}$ over $\mathrm{H}_{2} \mathrm{O}$ is defined as:

$$
\text { Separation factor }=\alpha_{p\left(\mathrm{HTO}_{\mathrm{H}} \mathrm{O}\right)}=\frac{C_{\mathrm{HTO}}^{\mathrm{P}} / C_{\mathrm{H}_{2} \mathrm{O}}^{\mathrm{O}}}{C_{\mathrm{HTO}}^{\mathrm{F}} / C_{\mathrm{H}_{2} \mathrm{O}}^{F}}=\frac{y_{\mathrm{HTO}}}{x_{\mathrm{HTO}}}
$$

where, $C_{H T O}^{P}$ and $C_{H_{2} O}^{P}$ are concentrations of $\mathrm{HTO}$ and $\mathrm{H}_{2} \mathrm{O}$ in the permeate, respectively, and $C_{H T O}^{F}$ and $\mathrm{C}_{\mathrm{H}_{2} \mathrm{O}}^{\mathrm{F}}$ are concentrations in the feed solution.

$$
\text { Ideal Selectivity }=\boldsymbol{S}_{\boldsymbol{P}}=\text { Permeance of } \mathrm{HTO}(\mathrm{GPU}) / \text { Permeance of } \mathrm{H}_{2} \mathrm{O}(\mathrm{GPU})
$$

The permeance (in $\mathrm{mol} / \mathrm{m}^{2} / \mathrm{s} / \mathrm{Pa}$, or alternatively in gas permeation units, $1 \mathrm{GPU}=3.348 \times 10^{-10}$ $\mathrm{mol} / \mathrm{m}^{2} / \mathrm{s} / \mathrm{Pa}$ ) of any species is obtained from the pervaporation equation:

$$
N_{i}=\bar{P}_{i}\left(x_{i} p_{i}^{*}-y_{i} P_{p}\right)
$$

Here $N_{i}$ is the experimentally obtained flux of species $i, x_{i}$ and $y_{i}$ are its mole fractions in the feed and permeate respectively, $p_{i}^{*}$ is the saturation vapor pressure of the species at the system temperature, $P_{p}$ is the permeate-side pressure, and $\overline{P_{i}}$ is its permeance through the membrane.

Since, in the case of LTA membranes, HTO in feed was retained/concentrated by molecular sieving and selective permeation of the $\mathrm{H}_{2} \mathrm{O}$ across the membrane, the separation factor and ideal selectivity definitions were modified as shown below. 


$$
\text { Separation factor }=\alpha_{F\left(H T O / H_{2} O\right.}=\frac{C_{H T O}^{F} / C_{H_{2} O}^{F}}{C_{H T O}^{P} / C_{H_{2} O}^{P}}=\frac{x_{H T O}}{y_{H T O}}
$$

Ideal Selectivity $=\boldsymbol{S}_{\boldsymbol{F}}=$ Permeance of $\mathrm{H}_{2} \mathrm{O}(\mathrm{GPU}) /$ Permeance of $\mathrm{HTO}(\mathrm{GPU})$

\subsection{Pervaporation experiments}

The schematic of the typical pervaporation system used for the permeation and separation measurements on disk molecular sieve zeolite membranes is shown in Figure 3. For the testing of the tubular membrane, a different appropriate membrane cell was used. The system consisted of a feed reservoir, a membrane test cell, and a cold trap to recover the condensed vapor on the permeate side of the membrane. The cold trap consisted of liquid nitrogen-cooled vessel. The vapor pressure of water at this temperature is nearly zero.

The feed volume was in the range of 1.5 to $3 \mathrm{~mL}$. Pervaporation experiments were performed at room temperature $\left(\sim 25^{\circ} \mathrm{C}\right)$. The effective membrane area of the disk membrane (1inch diameter) and tubular membrane (1 in long, 0.28 in diameter) was $2.85 \mathrm{~cm}^{2}$ and $5.6 \mathrm{~cm}^{2}$, respectively. The feed HTO concentration was approximately $1 \mathrm{mCi} / \mathrm{mL}(1 \mathrm{Ci} / \mathrm{L})$. This is consistent with the anticipated HTO concentration in the process water and acid recycle streams generated during the processing of used nuclear fuel.

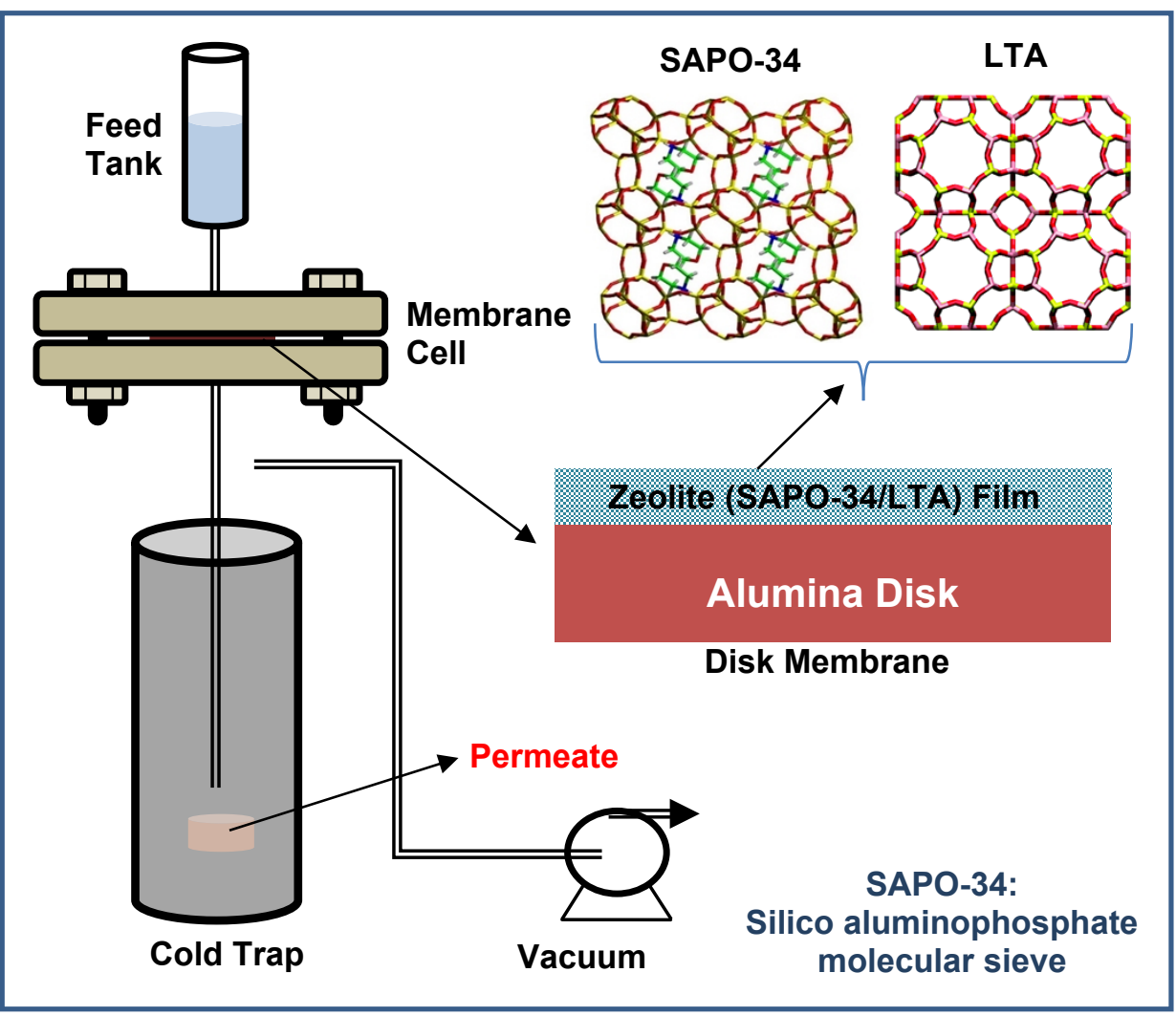

Figure 3. Schematic of the pervaporation system for the separation of tritiated water 


\section{RESULTS AND DISCUSSION}

In order to preferentially permeate HTO through the SAPO-34 membranes, several different monovalent and divalent cation-exchanged SAPO-34 membranes were fabricated and tested for $\mathrm{HTO} / \mathrm{H}_{2} \mathrm{O}$ separation. Table 1 shows the results of pervaporation experiments with both monovalent $\left(\mathrm{K}^{+}, \mathrm{Li}^{+}, \mathrm{Na}^{+}\right)$and divalent $\left(\mathrm{Co}^{2+}, \mathrm{Ba}^{2+}\right.$, and $\left.\mathrm{Sr}^{2+}\right)$ cations exchanged SAPO-34 zeolite membranes. Separation factor $\left(\mathrm{HTO} / \mathrm{H}_{2} \mathrm{O}\right)$ for the tritiated water separation with neutral SAPO-34 zeolite membrane was 0.83 which indicates that HTO did not preferentially permeate through zeolite pores over $\mathrm{H}_{2} \mathrm{O}$. The calculated $\mathrm{H}_{2} \mathrm{O}$ permeance was lower than HTO permeance resulting in the ideal selectivity value of $0.99(<1)$. However, upon cationexchange, the ideal selectivity for $\mathrm{HTO} / \mathrm{H}_{2} \mathrm{O}$ separation was higher than 1 for all cases. The increase in permeance for monovalent cation exchange membranes was significantly higher than that observed for divalent cation exchange membranes. This might be attributed to the number of divalent cations accessible to zeolite framework which is about half that of monovalent cations due to their valence. Therefore, the water molecules would be less strongly polarized and less strongly adsorbed to the divalent cation-exchanged SAPO-34 framework compared to monovalent cation-exchange SAPO-34, but more strongly adsorbed than neutral SAPO-34. ${ }^{12}$

Interestingly, all monovalent cation exchanged SAPO-34 membranes showed a substantial increase in vapor permeance for both components. Electronegativity of the oxygen atom in ion-exchanged SAPO-34 framework is higher than that in neutral SAPO-34 framework. Metal cations thus might have strong adsorption sites for water and tritiated water molecules via electrostatic interactions at the solid-water interface, since water molecules could be strongly polarized due to the high electronegativity of the oxygen atom in the framework. It was thought that this would lead to a strong interaction of water with cationic adsorption sites rather than with neutral surfaces of SAPO-34 zeolite, resulting in improved permeance of $\mathrm{H}_{2} \mathrm{O}$ and $\mathrm{HTO}$ molecules. ${ }^{12}$

Table 1. Vapor permeation characteristics of SAPO-34 and cation exchanged SAPO-34 membrane

\begin{tabular}{|c|c|c|c|c|c|c|c|}
\hline \multirow[t]{2}{*}{ Membrane } & \multirow[t]{2}{*}{ pH } & \multicolumn{2}{|c|}{$\begin{array}{l}\text { Radioactivity } \\
(\mathrm{mCi} / \mathrm{mL})\end{array}$} & \multicolumn{2}{|c|}{ Permeance (GPU) } & \multirow[t]{2}{*}{$\begin{array}{l}\text { Separation } \\
\text { factor }\left(\alpha_{P}\right)\end{array}$} & \multirow{2}{*}{$\begin{array}{c}\text { Ideal } \\
\text { Selectivity } \\
\left(\mathbf{S}_{\mathrm{P}}\right)\end{array}$} \\
\hline & & Retentate & Permeate & HTO & $\mathrm{H}_{2} \mathrm{O}$ & & \\
\hline SAPO-34 & 7 & 1.135 & 0.946 & 115.83 & 116.01 & 0.83 & 0.99 \\
\hline K-SAPO-34 & 7 & 1.162 & 1.189 & 2087.12 & 1701.52 & 1.023 & 1.23 \\
\hline Li-SAPO-34 & 7 & 1.165 & 1.122 & 2134.47 & 1849.56 & 0.96 & 1.15 \\
\hline Na-SAPO-34 & 7 & 1.178 & 1.135 & 1827.97 & 1583.27 & 0.96 & 1.15 \\
\hline Co-SAPO-34 & 7 & 1.216 & 1.081 & 348.88 & 327.54 & 0.89 & 1.07 \\
\hline Ba-SAPO-34 & 7 & 1.135 & 1.081 & 304.44 & 266.71 & 0.95 & 1.14 \\
\hline Sr-SAPO-34 & 7 & 1.135 & 1.081 & 172.13 & 150.80 & 0.95 & 1.14 \\
\hline
\end{tabular}

Although the separation mechanism is still not well understood, the significant increase in permeance and an increase in $\mathrm{HTO} / \mathrm{H}_{2} \mathrm{O}$ selectivity (above Knudsen diffusion) in cation exchanged SAPO-34 compared to neutral SAPO-34 can be attributed to the presence of new electrostatic interactions between $\mathrm{H}_{2} \mathrm{O} / \mathrm{HTO}$ and surface oxygen atoms of SAPO-34, and decreased pore sizes upon cation exchange. Unfortunately, with the SAPO-34 zeolites, there is a constraint (0.1-0.2 cations/Al atom) on how many cations can be exchanged limiting the variations in electrostatic interactions and also the pore sizes.

In order to take advantage of the effect of cation exchange and its beneficial impact on HTO permeance and selectivity, it was thought that cation exchanged LTA zeolite membrane could be a promising 
alternative. In the alumino-silicate framework of LTA, there is a negative charge available for each aluminum atom providing a significantly high exchange capacity of one cation per aluminum atom. In addition, the pore size of LTA zeolite can be decreased to about $0.3 \mathrm{~nm}$, for example when exchanged with potassium ${ }^{13}$. Through the quantum mechanics studies, it was shown that heavy water is more structured liquid than light water and the bond length of $\mathrm{H}_{2} \mathrm{O}$ is greater than that of $\mathrm{D}_{2} \mathrm{O}^{14}$. Another conspicuous difference between $\mathrm{H}_{2} \mathrm{O}$ and $\mathrm{HTO}$ is the frequency of stretching vibration of O-H and O-T bond which is inversely proportional to the reduced mass $\mu\left[\mu=m_{1} \cdot m_{2} /\left(m_{1}+m_{2}\right), m_{1}\right.$ and $m_{2}$ are masses of bonding atoms]. These identified differences resulting in varied interactions with cation exchanged LTA zeolite surface oxygen atoms and manipulated pore sizes could be utilized to enhance the $\mathrm{HTO} / \mathrm{H}_{2} \mathrm{O}$ selectivity. Interestingly, NaA zeolite (Na-LTA) has been already used in many commercial plants for the selective removal of water from solvents ${ }^{15}$.

Thus, in this study, cation exchanged LTA zeolite membranes were fabricated and evaluated both on the flat disk and tubular alumina supports. Table 2 shows the results of tritiated water pervaporation experiments using $\mathrm{Na}$ and $\mathrm{K}$ exchanged LTA membranes fabricated on the disk. Due to the highly hydrophilic nature of the LTA zeolites, it was expected the $\mathrm{H}_{2} \mathrm{O}$ permeance values for LTA membrane would be significantly higher compared to the SAPO-34. The reported values of the $\mathrm{H}_{2} \mathrm{O}$ permeance are typically $>10,000$ GPU. However, the observed values were similar to the cation exchanged SAPO-34 membranes (and somewhat lower in some cases) and about an order of magnitude lower than the reported vapor permeances of LTA membranes in the literature ${ }^{15}$.

Table 2. Separation of HTO with Na- and K-LTA zeolite membranes on disk supports

\begin{tabular}{|l|c|c|c|c|c|c|c|}
\hline Membrane & \multirow{2}{*}{$\mathbf{p H}$} & \multicolumn{2}{|c|}{$\begin{array}{c}\text { Radioactivity } \\
(\mathbf{m C i} / \mathbf{m L})\end{array}$} & \multicolumn{2}{c|}{ Permeance (GPU) } & $\begin{array}{c}\text { Separation } \\
\text { factor }\left(\boldsymbol{\alpha}_{\mathbf{P}}\right)\end{array}$ & $\begin{array}{c}\text { Ideal } \\
\text { Selectivity } \\
\left.\mathbf{( S}_{\mathbf{P}}\right)\end{array}$ \\
\cline { 3 - 8 } & & Retentate & Permeate & HTO & $\mathbf{H}_{\mathbf{2}} \mathbf{O}$ & & 1.14 \\
\hline Na-LTA-2 & 4 & 1.162 & 1.108 & 2427.39 & 2124.14 & 0.95 & 1.06 \\
\hline Na-LTA-3 & 4 & 1.162 & 1.027 & 720.7 & 680.6 & 0.88 & 1.02 \\
\hline K-LTA-1 & 4 & 1.108 & 0.946 & 1413.76 & 1382.2 & 0.85 & 0.96 \\
\hline
\end{tabular}

Furthermore, the ideal selectivity values close to 1 indicating that the membranes did not show selective permeation of the HTO over $\mathrm{H}_{2} \mathrm{O}$. While the general procedures for synthesis of LTA membranes are well established in the literature, these syntheses are often carried out using different kinds of supports. The type and quality of the support has a large impact on the resulting membrane quality. LTA membrane synthesized on CoorsTek porous disk supports showed some reactant gel penetration issues resulting in a thicker membrane layer. It is also thought that the larger pores ( $>0.5$ micron) in the symmetric (approximately $1 \mathrm{~mm}$ thick) support can result in the formation of inter-crystalline defects. It is believed that this could be the reason for the observed poor performance of $\mathrm{Na}$ and $\mathrm{K}$ exchanged LTA zeolite membrane fabricated on disk.

To overcome these difficulties an engineered asymmetric tubular alumina support with a thin smooth top layer of about $100 \mathrm{~nm}$ pore size was used to prevent gel penetration resulting in a thinner LTA layer. This approach enabled the preparation of high permeance LTA membranes with higher $\mathrm{HTO} / \mathrm{H}_{2} \mathrm{O}$ separation factor. To further confirm the quality of the membrane, a characterization step was added to perform ethanol-water separation experiments prior to evaluations on tritiated water. The measured ethanol-water separation factor was $>50$, and $\mathrm{H}_{2} \mathrm{O}$ permeance of $>20,000$ GPU. 
Table 3 summarizes the results of the $\mathrm{HTO} / \mathrm{H}_{2} \mathrm{O}$ separation experiments carried out using K-LTA zeolite membrane fabricated on tubular alumina support. The results showed that a significant improvement in the $\mathrm{HTO} / \mathrm{H}_{2} \mathrm{O}$ separation factor and ideal selectivity was observed with different samples of K-LTA membranes. It was also interesting to note that the K-LTA membranes selectively permeated the $\mathrm{H}_{2} \mathrm{O}$ instead of HTO resulting in higher concentration of HTO in retentate compared to the permeate. While the separation factor $\left(\alpha_{\mathrm{F}}\right)$ varied in the range of 1.28-2.79, ideal selectivity ranged between 1.07 to 2.33 . However, the experiment carried out at lower $\mathrm{pH}(\mathrm{pH} 4.5)$ showed significantly poor performance compared to the evaluations at neutral $\mathrm{pH}$. This could be attributed to the fact that LTA membranes with lower $\mathrm{Si} / \mathrm{Al}$ rations are susceptible to the irreversible leaching under acidic conditions ${ }^{16}$. LTA membrane synthesis and evaluation with more desired $\mathrm{Si} / \mathrm{Al}$ ratio to improve chemical resistance will be pursued in FY18.

Table 3. Separation of HTO with K-LTA zeolite membranes on tubular supports

\begin{tabular}{|c|l|c|c|c|c|c|c|c|c|}
\hline \multirow{2}{*}{} & Membrane & $\mathbf{p H}$ & \multicolumn{2}{|c|}{$\begin{array}{c}\text { Radioactivity } \\
\mathbf{( m C i / m L )}\end{array}$} & \multicolumn{2}{c|}{$\begin{array}{c}\text { Permeance } \\
(\mathbf{G P U})\end{array}$} & $\begin{array}{c}\text { Separation } \\
\text { Factor }\left(\boldsymbol{\alpha}_{\mathbf{F}}\right)\end{array}$ & $\begin{array}{c}\text { Ideal } \\
\text { Selectivity } \\
\left(\boldsymbol{S}_{F}\right)\end{array}$ & $\begin{array}{c}\text { \%HTO in } \\
\text { Permeate }\end{array}$ \\
\cline { 4 - 7 } $\mathbf{1}$ & & Keed & Permeate & HTO & $\mathbf{H}_{\mathbf{2}} \mathbf{O}$ & & 2.33 & 4.79 \\
\hline $\mathbf{2}$ & K-LTA-1-B1 & 4.5 & 1.027 & 0.973 & 19203 & 16913 & 1.06 & 0.88 & 10.34 \\
\hline $\mathbf{3}$ & K-LTA-1-B1 & 7 & 1.081 & 0.7838 & 9095 & 10474 & 1.38 & 1.15 & 19.6 \\
\hline $\mathbf{4}$ & K-LTA-1-B2 & 7 & 1.054 & 0.8108 & 5268 & 5717 & 1.3 & 1.09 & 11.35 \\
\hline $\mathbf{5}$ & K-LTA-1-B2 & 7 & 1 & 0.7838 & 5596 & 5960 & 1.28 & 1.07 & 12.06 \\
\hline $\mathbf{6}$ & K-LTA-1-B2 & 7 & 1.027 & 0.6756 & 4074 & 5171 & 1.52 & 1.27 & 26.35 \\
\hline $\mathbf{7}$ & K-LTA-1-B2 & 7 & 0.9189 & 0.6486 & 4983 & 5894 & 1.42 & 1.18 & 32.22 \\
\hline $\mathbf{8}$ & K-LTA-1-B2 & 7 & 1 & 0.5125 & 3423 & 5569 & 1.95 & 1.63 & 21.43 \\
\hline
\end{tabular}

It was also observed that, although the HTO concentration in permeate was significantly lower than in the feed, the retentate HTO concentration did not show the expected increase. In order to understand the underlying reason, a complete tritium material balance was done for each experiment as shown in Table 4. The $\Delta \mathrm{D}$ indicates total unaccounted amount of HTO which varied between 0.57 to $15.14 \%$ of HTO in feed. It is anticipated that there will be about $\pm 2-3 \%$ error in volumetric (experimental) and $1-2 \%$ error in LSA (analytical) measurements. Thus, based on the preliminary evaluations at this stage, it can be seen that most of the unaccounted HTO could be adsorbed in the K-LTA membrane layer and support structure. As shown in Table 4, a membrane tube soaked in $\mathrm{H}_{2} \mathrm{O}$ for 4-24 hours after the experiment showed some radioactivity and hence presence of HTO in the membrane. However, further detailed studies are required to understand this phenomenon and the mechanism of separation. Based on these results, we hypothesize that the mechanism of separation is a combination of molecular sieving and adsorption.

\section{Performance Comparison of SAPO and LTA membranes for the concentration of tritiated water}

The two key performance metrics for the separation of tritiated water are vapor permeance and selectivity. Higher selectivity for $\mathrm{HTO}$ over $\mathrm{H}_{2} \mathrm{O}$ would have a major impact on the separation efficiency as it will minimize the number of stages required to achieve the desired final concentration factor. On the other hand, a high vapor permeance is also essential for the economic viability as it has somewhat greater impact on the system size and cost. Efforts were focused both on optimization of permeation and separation properties of the synthesized membranes zeolite. 
Thus, as we can see from Table 4, with the LTA membrane the total vapor permeance in K-LTA is an order of magnitude higher (in the range of 10,000-20,000 GPU) than the SAPO-34. It is conceivable that with the high permeance LTA membrane and molecular sieving separation of tritiated water, a multistage cascade system would enable a cost-effective separation of tritiated water from high volume dilute aqueous solution compared to the current state of the art CECE system.

A more detailed techno-economic analysis and performance comparison with the CECE system will be discussed in a separate milestone report due at the end of September 2017.

Table 4. Material balance for HTO separation with K-LTA zeolite membranes on tubular supports

\begin{tabular}{|l|l|c|c|c|c|c|c|c|}
\hline & Membrane & $\mathbf{p H}$ & $\begin{array}{c}\text { Feed } \\
\mathbf{( m C i )}\end{array}$ & $\begin{array}{c}\text { Permeate } \\
\mathbf{( m C i )}\end{array}$ & $\begin{array}{c}\text { Retentate } \\
\mathbf{( m C i )}\end{array}$ & $\begin{array}{c}\mathbf{\Delta D} \\
\mathbf{( m C i )}\end{array}$ & $\begin{array}{c}\text { Recovered } \\
\text { from } \\
\text { membrane } \\
(\mathbf{m C i})\end{array}$ & $\begin{array}{c}\text { Unaccounted } \\
\text { HTO (\%) }\end{array}$ \\
\hline $\mathbf{1}$ & K-LTA-1-B1 & 7 & 3.1621 & 0.1514 & 2.7405 & 0.2703 & - & 8.55 \\
\hline $\mathbf{2}$ & K-LTA-1-B1 & 4.5 & 3.0811 & 0.3187 & 2.7447 & 0.0177 & - & 0.57 \\
\hline $\mathbf{3}$ & K-LTA-1-B1 & 7 & 3.2432 & 0.6358 & 2.2480 & 0.3595 & - & 11.08 \\
\hline $\mathbf{4}$ & K-LTA-1-B2 & 7 & 3.1621 & 0.3590 & 2.6263 & 0.1768 & - & 5.59 \\
\hline $\mathbf{5}$ & K-LTA-1-B2 & 7 & 3.0000 & 0.3618 & 2.5384 & 0.0998 & - & 3.33 \\
\hline $\mathbf{6}$ & K-LTA-1-B2 & 7 & 2.0541 & 0.5412 & 1.1990 & 0.3138 & 0.0486 & 12.91 \\
\hline $\mathbf{7}$ & K-LTA-1-B2 & 7 & 1.8378 & 0.5922 & 0.9401 & 0.3055 & 0.0272 & 15.14 \\
\hline $\mathbf{8}$ & K-LTA-1-B2 & 7 & 1.550 & 0.3322 & 1.005 & 0.2124 & 0.065 & 9.51 \\
\hline
\end{tabular}

$\Delta \mathrm{D}=($ Feed-Retentate)-Permeate

\section{FUTURE STUDIES}

In order to improve the selectivity and separation factor of $\mathrm{HTO} / \mathrm{H}_{2} \mathrm{O}$, several approaches will be pursued in FY18. (1) The effort on synthesis of improved ion exchange LTA zeolite membranes will be continued to further tune the self-diffusion coefficient of water versus HTO while reducing the membrane thickness. (2) The effect of Al-Si ratio in LTA (silicoaluminate) zeolites will be evaluated both to increase the selective adsorption and diffusion of $\mathrm{HTO}$ over $\mathrm{H}_{2} \mathrm{O}$ and to increase the chemical stability in acid contaminated water recycle streams. (3) Perform experiments to better understand the molecular sieving and adsorption mechanism.

Acknowledgements: The authors wish to thank Vishwanath Deshmane and Lawrence Powell (ORNL) for their extensive contributions in pervaporation experiments, Marc Chattin for Liquid Scintillation analysis, and Yeon Hye Kwon (graduate student at Georgia Tech) for her assistance in membrane synthesis and data analysis.

\section{REFERENCES}

1) Trznadel, G. Z., Tritium removal from water solutions, Desalination, 200, 737-738 (2006).

2) Ambashta, R. D., et al. Membrane purification in radioactive waste management: a short review, Journal of Environmental Radioactivity, 105, 76-84 (2012). 
3) Rana, D., et al. Radioactive decontamination of water by membrane processes- $A$ review, Desalination, 321, 77-92 (2013).

4) Butler, J.P. et al. Apparatus for removal and recovery of tritium from light and heavy water, US patent 4190515 (1980).

5) Bell, A.C., Perevenzentsev, A.N. Method and apparatus for concentrating tritiated water, European Patent Appl. EP 1,736,439 A2, December 27 (2006).

6) Drake, R.H., Recovery of tritium from tritiated waste water cost-effectiveness analysis, Los Alamos National Laboratory LA-UR-97-3767, June (1996).

7) Birdsell, S.A., et al. Tritium recovery from tritiated water with a two-stage palladium membrane reactor, Fusion Engineering and Design, 39-40, 1041-1048 (1998).

8) Embury, M.C., et al. Tritium recovery by cryogenic hydrogen isotope distillation, Proceedings of AIChE winter annual meeting, Miami, November 2-7 (1986).

9) Todorovic, M., et al. The release of tritiated water from cobalt (II) exchanged 4 A zeolite into surrounding water, Environmental Pollution (Series B) 7, 193-204 (1984).

10) Crawford, P., et al. Zeolite membranes for the separation of radioactive krypton and xenon, Proceedings of the Annual Meeting of the American Nuclear Society, Reno, June 15-19 (2014).

11) Wee, S., et al. Membrane separation process-pervaporation through zeolite membrane, Separation and Purification Technology, 63, 500-516 (2008).

12) Bhave, R., et. al. Investigation of Sorption and Diffusion Mechanisms, and Preliminary Economic Analysis, FCRD-MRWFD-2017-002026.

13) Wang N., et al. Hydrophilic SOD and LTA membranes for membrane-supported methanol, dimethylether and dimethylcarbonate synthesis., Microporous and Mesoporous Materials 207, 33 38 (2015).

14) Soper A. K. and Benmore C. J., Quantum Differences between Heavy and Light Water, Physical Review Letters 101(6), 065502 (2008).

15) Morigami, Y. et al., The first large-scale pervaporation plant using tubular-type module with zeolite NaA membrane separation, Separation \& Purification Technol., 25, 251-260 (2001).

16) Li Y., et al. Pervaporation and vapor permeation dehydration of Fischer-Tropsch mixed-alcohols by LTA zeolite membranes. Separation and Purification Technology 57, 140-146 (2007) 